\title{
Cost and Antibiotic Utilization of Pneumonia Patients in Intensive Care Unit
}

\author{
Ramya Kateel, Prabha Adhikari*, Sheetal Rajm \\ Department of Medicine, Kasturba Medical College, Mangalore, India.
}

\begin{tabular}{|c|c|}
\hline ARTICLE INFO & ABSTRACT \\
\hline $\begin{array}{l}\text { Article history: } \\
\text { Received on: } 16 / 10 / 2015 \\
\text { Revised on: } 17 / 12 / 2015 \\
\text { Accepted on: } 28 / 12 / 2015 \\
\text { Available online: } 27 / 02 / 2016\end{array}$ & $\begin{array}{l}\text { Objective of this study is to evaluate the cost and antibiotic utilization of pneumonia patients admitted in } \\
\text { intensive care unit. It was a retrospective study. Details required for antibiotic utilization and cost analysis were } \\
\text { acquired from hospital files. Out of } 320 \text { cases evaluated } 110 \text { cases were of pneumonia. } 28.2 \% \text { of people had } \\
\text { pneumonia as their primary diagnosis and } 71.8 \% \text { had hospital acquired/aspiration pneumonia. The mean length } \\
\text { of ICU stay was } 3.30 \pm 1.91 \text { days. } 21.8 \% \text { patients were put on ventilator. The mortality rate was } 34.5 \% \text {. } \\
\text { Betalactum along with betalactamase inhibitor antibiotics we prescribed for } 91 \% \text { patients Carbanenams for }\end{array}$ \\
\hline $\begin{array}{l}\text { Key words: } \\
\text { Pharmacoeconomics, } \\
\text { pneumonia, intensive care } \\
\text { unit, antibiotic utilization. }\end{array}$ & $\begin{array}{l}20 \% \text {, anti-staphylococcal antibiotic for } 51 \% \text { of patients and macrolides and miscellaneous antibiotics were } \\
\text { prescribed in } 25.5 \% \text { and } 36.4 \% \text { patients respectively. Betalactum antibiotic along with betalactamase inhibitor } \\
\text { and clindamycin combination was most commonly prescribed antibiotic. Average cost per patient who was not } \\
\text { put on ventilator was Rs } 27,123 \text { where as ventilated patient per cost was Rs } 44,812 \text {. This study showed that one } \\
\text { third of ICU admissions was due to pneumonia. Highest numbers of pneumonia were hospital acquired/aspiration } \\
\text { pneumonia. Cost of ventilator supported pneumonia was two times more than non-ventilated pneumonia. } \\
\text { Ventilator support was the most expensive intervention adding to the cost of care followed by cost of antibiotics } \\
\text { and investigations. }\end{array}$ \\
\hline
\end{tabular}

\section{INTRODUCTION}

Pneumonia is one of common cause of economic burden worldwide which involves significance utilization of health resources. It continues to be one of common cause of morbidity and mortality especially in geriatric group making it a major health problem worldwide (Richard et al, 2014; Garibaldi et al, 1985). It is one of the commonly diagnosed infections in intensive care unit with an incidence of $57.14 \%$ (Marrie, 1990; Pinner, 1996). Infectious Diseases Society of America/American Thoracic Society Consensus guidelines on the management of community-acquired pneumonia in adult suggest following antibiotic in intensive care unit, Betalactum antibiotic along with either azithromycin or respiratory fluoroquinolones, for Psuedomonal infection antipsuedomonal betalactum along with either macrolides or fluoroquinolones and for methicillin resistant staphylococcus infection addition of vancomycin or linezolid is recommended(Lionel, 2007). Intensive care unit admission is the major cost determinant entity among pneumonia

\footnotetext{
* Corresponding Author

Email: prabha.raghuveer@gmail.com
}

patients. Based on above data this study was planned to evaluate the antibiotic and cost utilization of pneumonia patients in Intensive Care Unit of Kasturba Medical College Hospital Mangalore.

\section{MATERIALS AND METHODS}

\section{Methodology}

Patient admitted to intensive care unit of Kasturba medical college hospital who had pneumonia during their stay in ICU were evaluated retrospectively for demographic data, indications, duration of ICU stay, drug utilized for pneumonia and status of patient when shifted out from ICU. Patients who were admitted in ICU during December 2013 to October 2014 were analyzed retrospectively. The study was approved by institutional ethics committee of Kasturba medical college Mangalore. To study antibiotic utilization all antibiotics were divided into 5 groups as shown in table 1. For Cost utilization ICU bed and nursing cost, ventilator cost, supportive cost, antibiotic cost, investigational cost, steroids and bronchodilator cost, organ support cost and miscellaneous cost were calculated. 
Costs per patient were calculated separately for ventilated/non ventilated patient and community acquired/ aspiration and hospital acquired pneumonia. Cost of pneumococcal and influenza vaccine was also calculated. All the results were expressed in percentage.

Table 1: Antibiotics Classification.

\begin{tabular}{ll}
\hline & Antibiotic \\
\hline Group I & Betalactum antibiotic along with betalactamase inhibior \\
GROUP II & Carbapenems \\
GROUP III & Antistaphylococcal antibiotics \\
GROUP IV & Macrolides \\
GROUP V & Miscellaneous \\
\hline
\end{tabular}

\section{RESULTS AND DISCUSSION}

Out of 320 consecutive cases of ICU evaluated 110 cases were of pneumonia. Indicating that nearly one third of admissions to ICU are due to Pneumonia their details are given in table 2.

$92.45 \%$ of patients had other co morbidities. The important once are given below in table 3 .

\begin{tabular}{ll} 
Table 2: Patient details. & \\
\hline Age (median) & $65(44,74)$ \\
Sex & Male 63.6\%(70) \\
& Female 36.4(40 \\
Ventilator support & $21.8 \%(15)$ \\
Mortality & $33.9 \%(38)$ \\
Mean length of ICU stay & $3.30 \pm 1.91$ days \\
Community acquired pneumonia & $28.2 \%(31)$ \\
Hospital acquired/ aspiration pneumonia & $71.8 \%(79)$ \\
\hline
\end{tabular}

\begin{tabular}{ll} 
Table 3: Co Morbidities. & \\
\hline Cardiovascular disease & $45 \%$ \\
Diabetes mellitus & $40 \%$ \\
COPD & $25 \%$ \\
HIV/AIDS & $25 \%$ \\
Carcinoma & $10 \%$ \\
Chronic kidney injury & $12 \%$ \\
Others & $28 \%$ \\
\hline
\end{tabular}

Mortality was observed in $33.9 \%$ ( 38) patients out of which $18.6 \%$ (21) had aspiration pneumonia/ hospital acquired pneumonia and $15.2 \%$ (17) had community acquired pneumonia. . Pneumonia was primary cause of death in $36.8 \%$ (14) of patients, it was antecedent cause of death in $55.26 \%$ (21) patients, in 7.89 $\%$ ( 3) of patients it contributed as other significant cause of death with other co morbidity being primary cause. Both groups had organ failure which was $19.4 \%$ in community acquired and $27.8 \%$ in aspiration/ hospital acquired pneumonia.

Antibiotics utilized in Intensive Care Unit for pneumonia patients are as given in table 4 . Betalactum antibiotic along with a betalactamase inhibitor was used in $91 \%$ of patient. Combination of this with anti-staphylococcal antibiotic was common regimen. Another important combination was betalactum antibiotic with macrolides. Mean cost of pneumonia treatment per patient for an average stay of 3 days in ICU in this study is given in table 5. Cost utilization in each category was calculated separately for community acquired and hospital/aspiration pneumonia. Total cost of pneumonia treatment was categorized into 6 categories and percentage utilization was calculated in each category. It was calculated separately for community acquired pneumonia, hospital/ aspiration pneumonia, ventilated pneumonia and for nonventilated pneumonia patients. Details are given in graph 1 and graph 2 .

Table 4: Antibiotic Utilization.

\begin{tabular}{lll}
\hline Group & Antibiotic & Utilization \\
\hline GROUP I & Betalactum antibiotic + betalactamase inhibitor & $91 \%(100)$ \\
GROUP II & Carbapenems & $20 \%(22)$ \\
GROUP III & Anti Staphylococcal Antibiotic & $51 \%(56)$ \\
GROUP IV & Macrolides & $25.5 \%(36)$ \\
GROUP V & Miscellaneous & $36.4 \%(40)$ \\
\hline
\end{tabular}

Table 5: Mean cost of pneumonia treatment.

\begin{tabular}{ll}
\hline Type of pneumonia & Per patient cost \\
\hline Community acquired pneumonia & Rs. 35573/- \\
Aspiration/ hospital acquired pneumonia & Rs. 31129/- \\
Ventilated pneumonia & Rs.44812/- \\
Non ventilated pneumonia & Rs. 27123/- \\
\hline
\end{tabular}

Pneumonia is a serious and widespread infection due to its high incidence, morbidity, mortality and increased health care costs. It is one of the commonly diagnosed infections in intensive care unit with an incidence of 57.14\%( Almirall, 1995). In this study out of 320 cases admitted to intensive care unit 110 patients had pneumonia. $28.2 \%$ ( 31) patients had community acquired pneumonia whereas aspiration/hospital acquired pneumonia was seen in $71.8 \%$ ( 79) patients. Total of $85 \%$ of patients presented with other co morbidities. $45 \%$ of patient had cardiovascular disease, $40 \%$ had diabetes mellitus, 25\% had COPD and HIV/AIDS, $10 \%$ had carcinoma, $12 \%$ had chronic kidney injury, and $28 \%$ had other miscellaneous co morbidities. The mortality rate was $33.9 \%$ it was more in aspiration/ hospital acquired pneumonia (18.6\%) compared to community acquired (15.2\%). It was observed that in $36.8 \%$ of patients pneumonia was primary cause for death and in $55.26 \%$ patients it was an antecedent cause of death and in $7.89 \%$ of patients pneumonia was other significant cause of death. Both groups had Organ failure, $19.4 \%$ in community acquired and $27.8 \%$ in aspiration/ hospital acquired pneumonia. Mortality rate was high in our study since median age of patients was 65 and was presented with many other co morbidities.

Betalactum antibiotic along with a betalactamase inhibitor was used in $91 \%$ of patient. Combination of this with anti-staphylococcal antibiotic was common regimen, in few patients addition of macrolides were done. These were in accordance with Infectious Diseases Society of America/American Thoracic Society Consensus Guidelines on the Management of Community-Acquired Pneumonia in Adults (Lionel, 2007). Carbapenams was costliest antibiotic which was used in $20 \%$ patients; dose escalation was seen in $15.2 \%$ of patients.

Pharmacoeconomic studies of pneumonia have shown that intensive care unit is the one of the major cost determinant in pneumonia patients (Raymond, 2003). Hence in this study we evaluated the cost utilization of pneumonia patients in Intensive Care Unit. Cost for ventilated and non-ventilated patients was calculated separately. 


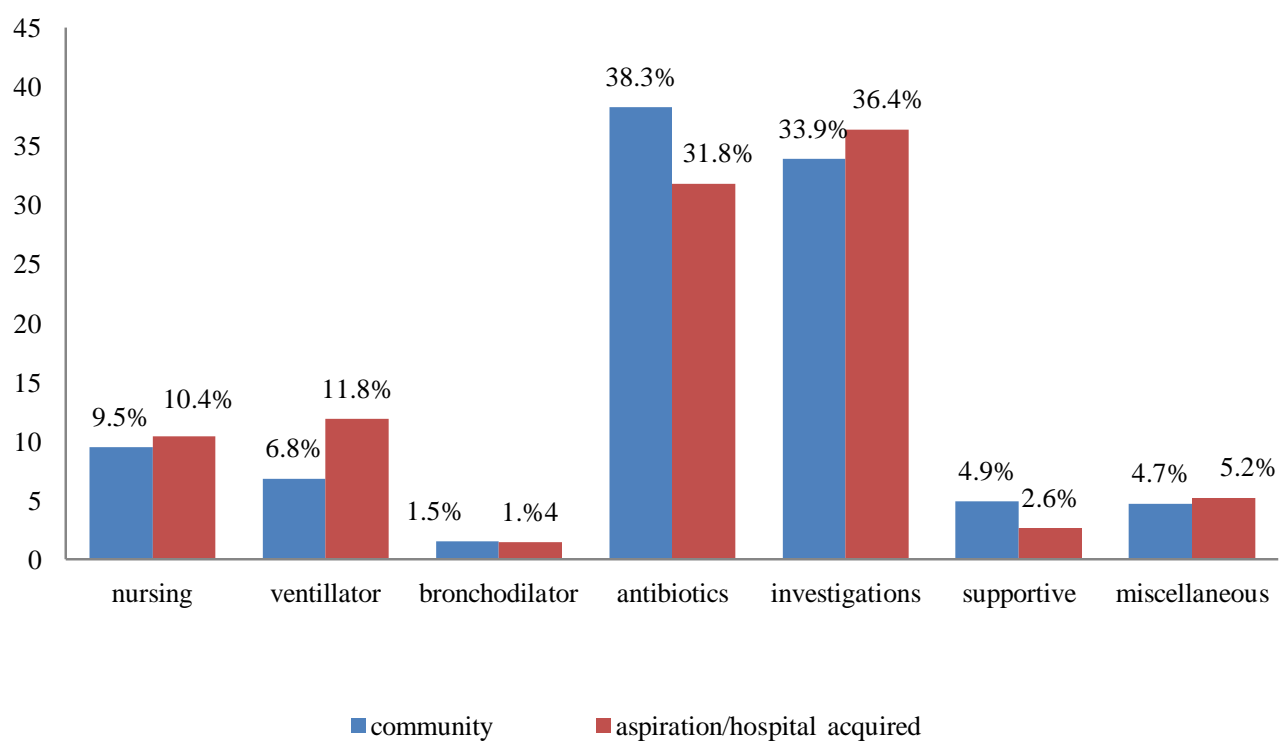

Graph 1: Cost utilization (\%) in community and aspiration/ hospital acquired pneumonia.

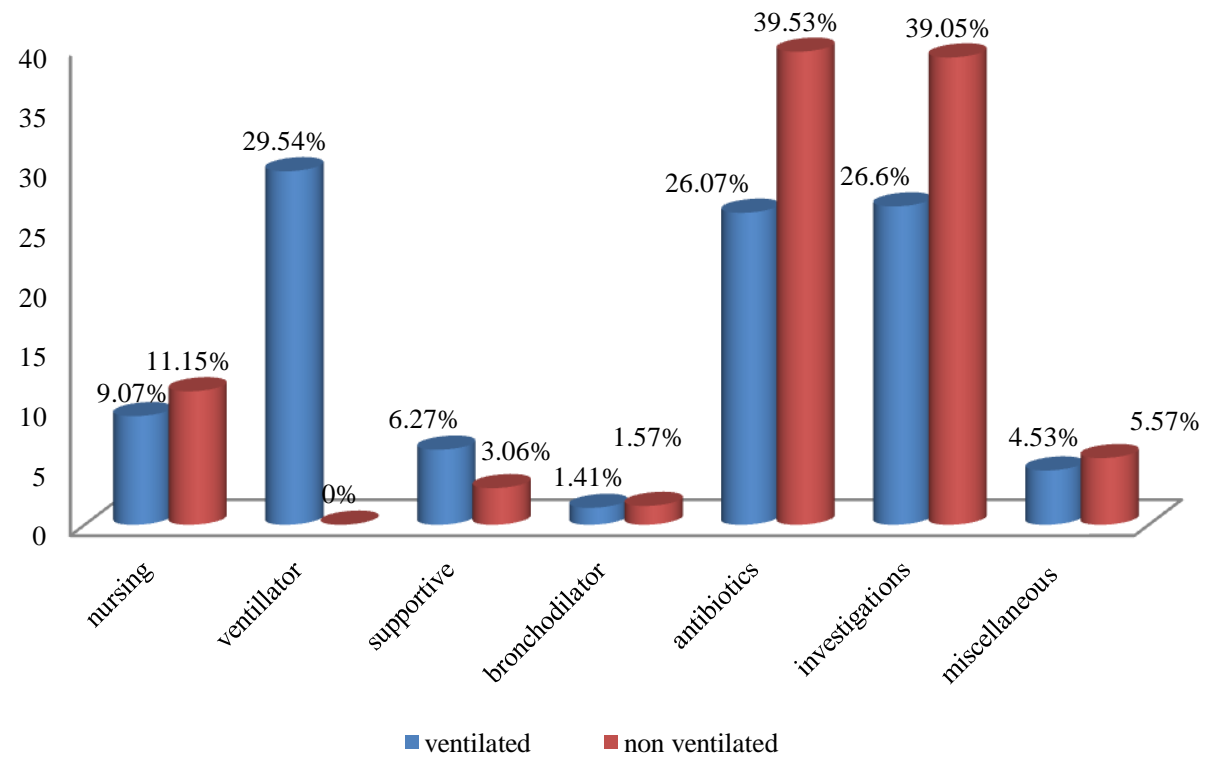

Graph 2: Cost utilization (\%) of ventilated/ non ventilated pneumonia patient.

Per patient cost of ventilated patient (Rs.44812/) was almost two times more than non-ventilated patient (Rs. 27123/). Ventilator support was the major cost drawing entity in ICU. In the absence of ventilator, antibiotics were highest cost utilization group but total cost of this was almost $40 \%$ less in patients without ventilator. So use of Costlier antibiotics in ICU may be justified as cost effective since Cost of investigations and antibiotics were higher in non-ventilated patients indicating the early use of higher antibiotics and investigations may reduce the need for ventilator provided it prevents patient undergoing ventilation. Cost for community and aspiration/hospital acquired pneumonia were similar. Per patient cost of community acquired pneumonia was Rs. 35573/ and for aspiration/ hospital acquired pneumonia was Rs. 31129/. In both the groups highest cost was utilized for antibiotics i.e. $38.3 \%$ and $31.8 \%$ in Community acquired pneumonia and Aspiration pneumonia/Hospital Acquired Pneumonia respectively followed by investigational charges which were $33.9 \%$ and $36.4 \%$ of total cost. Community acquired pneumonia can be prevented by vaccination with pneumococcal and influenza vaccine, even though there is contradictory data regarding its efficacy in preventing Community acquired pneumonia (Nichol, 1996; Kwetkat, 2015) it is still recommended by Center for Disease Control and prevention (CDC, 2015) to have pneumococcal vaccine one dose and influenza vaccine once in a 
year after 65 years of age. The cost of these vaccine may come around Rs. 4810/ which is much lesser than cost of Community Acquired Pneumonia i.e. Rs. 35573. Since the median age of our study population was 65 , vaccinating them would be an appropriate measure (Dirmesropian, 2015).

Since the median age of our study population is 65 and most of them were present with comorbidities such as cancer, diabetes, HIV/AIDS increasing the risk of aspiration in the hospital. Simple measures like bed positioning, dietary changes and oral hygiene etc. may prevent aspiration (Ottosen, 2014; DiBardino, 2015). This may require appointment of a special trained nurse which is cost effective compared to total cost of pneumonia.

\section{CONCLUSION}

This study showed that one third of ICU admissions were due to pneumonia out of which $28.2 \%$ was the primary diagnosis and in $71.8 \%$ patients Aspiration pneumonia secondary to co morbid conditions were seen. Mortality in both community acquired pneumonia and hospital acquired pneumonia or aspiration pneumonia was very high due to age and other co morbidity. Betalactum antibiotic along with a beta lactamase inhibitor was used in $91 \%$ of patient. Combination of this with anti-staphylococcal antibiotic was common regimen used. Cost of care for both community and aspiration pneumonia in the ICU were approximately same. Cost of ventilator supported pneumonia was two times more than non-ventilated pneumonia. Ventilator support was the most expensive intervention in ICU followed by cost of antibiotics and investigations.

\section{REFERENCES}

Richard G, Wunderink M D, Grant W Waterer. Community acquired pneumonia. N Engl J Med, 2014; 370:543-551.
Garibaldi RA: Epidemiology of community-acquired respiratory tract infections in adults: Incidences, etiology, and impact. Am J Med, 1985;78:32-37S:

Marrie TJ: Epidemiology of community-acquired pneumonia in the elderly. SeminRespir Infect, 1990; 5:260-268.

Pinner RW, Teutsch SM, Simonsen L, et al. Trends in infectious diseases mortality in the United States. JAMA, 1996; 275:189-193.

Lionel A. Mandell, Richard G. Wunderink, Antonio Anzueto, John G. Bartlett, G. Douglas Campbell, Nathan C. Dean etal. Infectious Diseases Society of America/American Thoracic Society Consensus Guidelines on the Management of Community-Acquired Pneumonia in Adults. Clinical Infectious Diseases, 2007; 44: S27-72.

Almirall J, Mesalles E, Klamburg J, et al: Prognostic factors of pneumonia requiring admission to the intensive care unit. Chest, 1995;107:511-516.

Raymond J Foley, Mark L Metersky. Cost-effectiveness of community-acquired pneumonia therapy. Expert Review on Pharmacoeconomics and Outcome Reseach, 2003;3: 749-56.

Nichol KL, Margolis KL, Wouremma J, et al. Effectiveness of the influenza vaccine in the elderly. Gerontology, 1996; 42: 274-279.

Kwetkat A1, Hagel S, Forstner C, Pletz MW. Pneumococcal vaccination for prevention of pneumonia. Z Gerontol Geriatr, 2015;12:1-5.

Recommended Immunizations for Adults: By Health Condition. 2015. (ONLINE) available at: http://www.cdc.gov/vaccines/adults/recvac/index.html?s_cid=cs_650.

Dirmesropian S1, Wood JG, MacIntyre CR, Newall AT. A review of economic evaluations of 13 -valent pneumococcal conjugate vaccine (PCV13) in adults and the elderly. Hum VaccinImmunother, $2015 ; 11: 818-25$.

Ottosen J, Evans H. Pneumonia: challenges in the definition, diagnosis, and management of disease. Surg Clin North Am, 2014; 94:1305-17.

DiBardino D M, Wunderink R G. Aspiration pneumonia: a review of modern trends. J Crit Care, 2015; 30:40-8.

\section{How to cite this article:}

Ramya K, Adhikari P, Rajm S. Cost and Antibiotic Utilization of Pneumonia Patients in Intensive Care Unit. J App Pharm Sci, 2016; 6 (02): 087-090. 